\title{
Assessment of Nutritional Status of Preschool Children: Head Circumference and Other Anthropometric Indices
}

\author{
Yeasmin $\mathrm{K}^{1^{*}}$, Yeasmin $\mathrm{T}^{2}$ \\ ${ }^{1}$ Institute of Biological Sciences, University of Rajshahi, Rajshahi, Bangladesh; ${ }^{2}$ Department of Biochemistry \\ and Molecular Biology, University of Rajshahi, Rajshahi, Bangladesh
}

\begin{abstract}
Background: Undernutrition is one of the major responsible factors of morbidity and mortality among preschool children in the most developing countries. Weight for age Z-score (WAZ), height for age Z-score (HAZ) and weigh for height Z-score (WHZ) are widely used for indicating nutritional status of children. Therefore, the study was conducted to interpret the nutritional status based on head circumference for age $\mathrm{z}$ score (HCAZ), WAZ, HAZ and WHZ among children aged from 36 to 71 months in Rajshahi City area, Bangladesh.

Methods: This cross-sectional study included one thousand and thirty five preschool children. Of them, 538 were boys and 497 were girls. Data were collected during the period of March 2017 to March 2018, using multistage random sampling method. Head circumference $(\mathrm{HC})$ was measured $(\mathrm{cm})$ and HC-for-age Z-score (HCAZ) was calculated according to World Health Organization recommendations. Z-score values of $\mathrm{HC}<-2$ standard deviation below from the reference population were considered as undernourished. $\mathrm{Z}$ score $-3<\mathrm{HC}<-2$ standard deviation were taken as moderately undernourished whereas, ' $\leq-3$ ' standard deviation were considered as severely undernourished, respectively.

Results: Among boys the mean age and HC were $53.58 \pm 10.68$ and $48.62 \pm 1.87$ whereas, among girls the mean age and $\mathrm{HC}$ were $51.35 \pm 11.17$ and $48.00 \pm 1.84$ respectively. According to $\mathrm{HC}$, the rate of moderate and severe malnourished children among boys were $33.3 \%$ and $6.3 \%$ and among girls $30 \%$ and $13.5 \%$ respectively. The prevalence of malnutrition was higher according to $\mathrm{HC}$ for age in comparison to other parameters. The study revealed that $33.3 \%$ and $12.4 \%$ stunted, $41.3 \%$ and $12.7 \%$ underweight and $41.9 \%$ and $9.5 \%$ wasted children were moderately malnourished and severely malnourished according to HC respectively. The relationship between these three indicators and $\mathrm{HC}$ for age were statistically significant.

Conclusion: As head circumference (HC) is a reliable physical index of both past nutritional situation and brain development and important indicator for measuring nutritional status, routine measurement and intervention for assessing and removing undernutrition is to be recommended.
\end{abstract}

Keywords: Head circumference, Undernutrition, Preschool children

\section{Introduction}

Undernutrition is a major public health problem highlighted by the 2015 Sustainable Development Goals, hopeful to end hunger by 2030. ${ }^{1}$ Nutritional status and health development of child are measured by child's growth. ${ }^{2}$ About 13 million infants and children under 5 years of age die in developing countries in every year. Most of these deaths link to malnutrition and over three-quarters

*Correspondence: Kumkum Yeasmin, Institute of Biological Sciences, University of Rajshahi, Rajshahi, Bangladesh; e-mail: yeasmin_bio@yahoo.com ORCID: https://orcid.org/0000-0003-4407-8224 of the world's malnourished children live in the Southeast Asia region. About half of child deaths are occurred to malnutrition's side effect and more than $80 \%$ are attributable to mild to moderate malnutrition. ${ }^{3}$ In Bangladesh six million children found to be chronically undernourished. ${ }^{4}$ The decline in chronic malnutrition seen previously from $60 \%$ in 1997 to $41 \%$ in 2011 - now appears to be slowing down, more than half of children are born with low birth weight, and $36.2 \%$ children are stunted, $15 \%$ are wasted and $33 \%$ are 
underweight. $^{5}$ Prevalence of stunting or underweight is lowest amongst $0-6$ months aged children, whereas highest at the age of 18 to 23 months (stunted 48\% and underweight 37\%) however, wasting is highest in $0-6$ months and have an enlarged risk of death from infectious diseases. $^{6,7}$

Assessment of growth is the sole best measurement for evaluating child health and nutritional status and it symbolizes an indirect dimension of the quality of life of an entire population. $^{8}$ The assessment of growth, more particularly the measurement of the head circumference is a vital part of the Paediatric Neurological Examination. Very important information can be suggested from the head size and shape that will guide the differential diagnosis and the need for further investigations. Head circumference (HC) is a simple and noninvasive anthropometric measure. Also known as the frontal occipital circumference, $\mathrm{HC}$ has been cautiously used to assess the prevalence of undernutrition among pre-school children. ${ }^{9}$ This circumference is an indicator of cranial growth and is also considered to be an indicator of past nutritional status and development of the brain and brain size. $^{10-12}$

Head circumference (HC) is a reliable physical index of both past nutritional situation and brain development and in pediatrics; it is routine measurement to assess brain development since it is an indicator of microcephaly and macrocephaly according to $\mathrm{HC}$ percentile in brain pathology. ${ }^{13}$ Malnutrition alters brain development and cognitive development by interfering with overall health as well as with child energy level, rate of motor development and growth. Poverty and deprivation accelerate these negative effects, especially when mothers have lower schooling levels. $^{14}$

Head circumference (HC) during birth reveals intrauterine growth and permits for proper assessment of fetal growth and also used as a substitute measure for brain development (both intrauterine and from birth), and can be extrapolative of some child outcomes. ${ }^{15}$

Undernutrition during infancy and childhood substantially raises susceptibility to infection and disease and increases the risk of premature death. ${ }^{16}$ Malnutrition during childhood can also affect the growth potential and the risk of morbidity and mortality in later years of life. ${ }^{17,18}$

From a lot of literature review, it has been observed that malnutrition using head circumference for age among pre-school children in Rajshahi city was not found. Hence, study was conducted with the aim to interpret the nutritional status based on head circumference (HC), WAZ, HAZ and WHZ among children aged from 36 to 71 months in Rajshahi city area in Bangladesh.

\section{Materials and Methods}

This cross-sectional study was carried out in Rajshahi City Corporation area, Bangladesh. All pre-school children were study population in Rajshahi city, Bangladesh. Multistage random sampling with proportion allocation utilized in this study. The sample size was calculated using a single proportion formula by using $41.4 \%$ of prevalence of malnutrition in Rajshahi City, 95\% confidence interval (CI), marginal of error $5 \%$ and $10 \%$ non-response rate were added to the total sample size was computed.

A Z-value of 1.96 used at $95 \%$ CI and d of $5 \%$. $(\mathrm{n}=$ sample size, $p=$ prevalence, $\mathrm{d}=$ margin of error).

$\mathrm{n}=\mathrm{Z}^{2} \mathrm{p}(1-\mathrm{p})=(1.962 \times 0.414)(1-0.414)=373$

$\mathrm{d}^{2}=0.052^{19}$

So, considering for non-response $\quad(20 \%$ contingency) $\mathrm{n}=(373+74)=447$, and again multiplied by design effect 2 , the final sampling size was 894 children. However, for ensuring the validity as well as reliability and avoiding ambiguity, the study selected finally 1056 households with pre-school children. In conclusion, for the disagreement of 21 respondents, one thousand and thirty five study population were studied.

Ethical clearance was obtained from the Institutional Animal, Medical Ethics, Biosafety and Biosecurity Committee (IAMEBBC) for Experiments on Animal, Human, Microbes and Living Natural Sources of Institute of Biological Sciences, University of Rajshahi, Bangladesh. 
Both verbal and written consent of the corresponding household guardian were obtained. Study included 1035 pre-school children in Rajshahi city with age range 36 to 71 months ( $36 \leq$ Age $\leq 71$ months) of whom 538 were boys and 497 were girls. The data collection period was from March 2017 to March 2018. The mothers or caregivers who had children with age range 36 to 71 months and giving voluntary consent to participate in the study had been included. About children, who were mentally not disabled and free from serious diseases were included. Mentally disabled children and who were unwilling to participate in this study were excluded. Head circumference was measured by the standard anthropometric procedures using a flexible, non stretch plastic coated tape. ${ }^{20}$ Tape was passed over the supraciliary ridges in front and maximum occipital protuberance at the back in such a way as to get maximum HC. The measurements were taken to the nearest $0.1 \mathrm{~cm}$. Assessment of nutritional status was done using WHO child growth standards sex and age specific $Z$ score values. $Z$ score $<-2$ standard deviation was considered as moderate malnutrition and $\mathrm{Z}$ score $<-3$ standard deviation was considered as severe malnutrition. $^{21}$

A pre-coded standard questionnaire was developed for obtaining valid information on socio-economic and demographic condition such as age, sex, number of children, parental educational qualification, economic status, occupations, environmental sanitation, expenditure for household purposes etc. Anthropometric measurements were taken by using standard techniques. A weight balance was used to measure body weight. The balance was standardized before using. The body weight of child and mother was measured bare footed, almost empty stomach and thin dressed to the nearest $0.1 \mathrm{Kg}$. Height of the sample measured was measured by using height scale to the nearest $0.1 \mathrm{~cm}$, without any shoes and standing straight. MUAC of the children was measured by using a flexible and non-stretchable plastic tape. Stunting, wasting and underweight was calculated using the WHO Multicenter Growth Reference Standard. Children with a measurement of $<-1$ SD (1.99 SD to $-1.00 \mathrm{SD}),<-2 \mathrm{SD}(-2.99 \mathrm{SD}$ to $-2.00 \mathrm{SD})$ and $<-3 \mathrm{SD}(\leq-3.00 \mathrm{SD})$ units from the median of the reference population were considered as mild malnutrition, moderate malnutrition and severely malnutrition were categories respectively. ${ }^{21}$ Children "stunted" and "not stunted", "wasted" and "not wasted", "underweight" and "not underweight" according to three anthropometric indicators. The data were statistically analysed using the Statistical Package for Social Sciences (SPSS). Base line characteristics of study population were measured by descriptive statistics. Chi square analysis $\left(\chi^{2}\right)$ was done to evaluate sex differences in moderate and severe grades of under-nutrition among children. All statistical tests were carried out at the $5 \%$ significance level.

\section{Results}

The study was conducted among 1035 preschool children from which $538(52.0 \%)$ were boys and $497(48.0 \%)$ were girls. The mean age of the children was $52.5 \pm 11.0$ months with minimum and maximum of 36 to 71 months respectively.

Table I: Distribution of population based on socio-demographic factors

\begin{tabular}{|c|c|c|}
\hline & No $(\mathbf{N})$ & $\%$ \\
\hline \multicolumn{3}{|l|}{ Gender } \\
\hline Boys & 538 & $52.0 \%$ \\
\hline Girls & 497 & $48.0 \%$ \\
\hline \multicolumn{3}{|c|}{ Age of children in months } \\
\hline $36-47$ & 382 & $36.9 \%$ \\
\hline $48-59$ & 345 & $33.3 \%$ \\
\hline $60-71$ & 308 & $29.8 \%$ \\
\hline \multicolumn{3}{|l|}{ Family structure } \\
\hline Joint & 390 & $37.7 \%$ \\
\hline Nuclear & 645 & $62.3 \%$ \\
\hline \multicolumn{3}{|l|}{ Family members } \\
\hline$<=4$ & 575 & $55.6 \%$ \\
\hline $5-6$ & 222 & $21.4 \%$ \\
\hline$>=7$ & 238 & $23.0 \%$ \\
\hline \multicolumn{3}{|l|}{ Family income } \\
\hline$<10000$ & 441 & $42.6 \%$ \\
\hline $11000-20000$ & 266 & $25.7 \%$ \\
\hline $21000-40000$ & 254 & $24.5 \%$ \\
\hline$>40000$ & 74 & $7.1 \%$ \\
\hline \multicolumn{3}{|l|}{ Socio - economic class } \\
\hline Poor & 434 & $41.9 \%$ \\
\hline Lower middle & 285 & $27.5 \%$ \\
\hline Upper middle & 227 & $21.9 \%$ \\
\hline High & 89 & $8.6 \%$ \\
\hline \multicolumn{3}{|l|}{ Education level of father } \\
\hline No education & 136 & $13.1 \%$ \\
\hline Primary and secondary & 324 & $31.3 \%$ \\
\hline $\mathrm{SSC}$ and HSC & 225 & $21.7 \%$ \\
\hline Higher education & 350 & $33.8 \%$ \\
\hline \multicolumn{3}{|c|}{ Education level of mother } \\
\hline No education & 132 & $12.8 \%$ \\
\hline Primary and secondary & 364 & $35.2 \%$ \\
\hline $\mathrm{SSC}$ and $\mathrm{HSC}$ & 267 & $25.8 \%$ \\
\hline Higher education & 272 & $26.3 \%$ \\
\hline \multicolumn{3}{|l|}{ Weight during birth } \\
\hline$<2500$ & 464 & $44.8 \%$ \\
\hline $2500-3500$ & 518 & $50.0 \%$ \\
\hline$>3500$ & 53 & $5.1 \%$ \\
\hline \multicolumn{3}{|l|}{ Living condition } \\
\hline Kacha & 282 & $27.2 \%$ \\
\hline Semi pacca & 341 & $32.9 \%$ \\
\hline Building & 412 & $39.8 \%$ \\
\hline \multicolumn{3}{|c|}{ Exclusive Breast Feeding } \\
\hline No & 406 & $39.2 \%$ \\
\hline Yes & 629 & $60.8 \%$ \\
\hline
\end{tabular}


Nearly four tenth $(37.7 \%)$ of children lived in joint families, whereas $62.3 \%$ children's family structure was nuclear. More than one fourth of respondent's families lived in "kacha" houses and nearly one third families lived in "semi pucca" houses. Less than one tenth $(7.0 \%)$ of the families were earning more than 40,000 taka as monthly income. Almost $69.5 \%$ families came from poor and lower middle socioeconomic class. It was observed that $44.8 \%$ children had low weight $(<2500 \mathrm{gm})$.

According to HCAZ, $33.3 \%$ of boys and $30.0 \%$ of girls were moderately malnourished and on the other hand, 6.3 of boys and $13.5 \%$ of girls were severely malnourished. Chi-square test revealed that the association between HCAZ and gender was statistically significant $(p<0.01)$. Phi and Cramer's $\mathrm{V}$ test demonstrated that the relation between HCAZ and gender was strong $(p<0.01)$ (table II).

Table II: Association between gender and head circumference for age Z-score (HCAZ)

\begin{tabular}{|c|c|c|c|c|c|c|}
\hline \multirow{2}{*}{ Gender } & \multicolumn{3}{|c|}{ Head circumference for age Z-score } & \multirow[b]{2}{*}{ Total } & \multirow[b]{2}{*}{$\chi^{2}$} & \multirow[b]{2}{*}{$p$ value } \\
\hline & A & B & $\mathrm{C}$ & & & \\
\hline \multirow{2}{*}{ Boys } & 179 & 34 & 325 & 538 & \multirow{4}{*}{15.12} & \multirow{4}{*}{0.001} \\
\hline & $33.3 \%$ & $6.3 \%$ & $60.4 \%$ & $100.0 \%$ & & \\
\hline \multirow{2}{*}{ Girls } & 149 & 67 & 281 & 497 & & \\
\hline & $30.0 \%$ & $13.5 \%$ & $56.5 \%$ & $100.0 \%$ & & \\
\hline
\end{tabular}

*Note: $\mathrm{A}=$ Moderate Malnourished, $\mathrm{B}=$ Severe Malnourished, $\mathrm{C}$ $=$ Normal

Mean $( \pm \mathrm{SD})$ weight of the total sample population (n 1035) was $15.22( \pm 3.44) \mathrm{kg}$ with the range of 8 to $27 \mathrm{~kg}$. Mean $( \pm$ SD) height $(\mathrm{n}=1035)$ was 100.39 $( \pm 9.05)$ with the range of 72 to $122 \mathrm{~cm}$. It was observed that the average height and weight among boys were greater than that of girls (table III).

Table III: Mean weight and height of the children

\begin{tabular}{|c|c|c|c|c|c|c|c|}
\hline A & Gender & B & $\mathbf{N}$ & Min & Max & Mean & SD \\
\hline \multirow{4}{*}{$36-47$} & \multirow{2}{*}{ Boys } & Height $(\mathrm{cm})$ & 189 & 72 & 107 & 93.71 & 6.64 \\
\hline & & Weight (kg) & 189 & 8 & 21 & 13.91 & 2.43 \\
\hline & \multirow{2}{*}{ Girls } & Height $(\mathrm{cm})$ & 193 & 72 & 106 & 91.95 & 5.25 \\
\hline & & Weight (kg) & 193 & 9.3 & 18 & 12.86 & 2.07 \\
\hline \multirow{4}{*}{$48-59$} & \multirow{2}{*}{ Boys } & Height $(\mathrm{cm})$ & 167 & 88 & 114 & 101.66 & 5.94 \\
\hline & & Weight (kg) & 167 & 9 & 27 & 15.20 & 2.74 \\
\hline & \multirow{2}{*}{ Girls } & Height $(\mathrm{cm})$ & 178 & 88.2 & 118 & 100.04 & 6.32 \\
\hline & & Weight (kg) & 178 & 10 & 26 & 14.84 & 3.22 \\
\hline \multirow{4}{*}{$60-71$} & \multirow{2}{*}{ Boys } & Height $(\mathrm{cm})$ & 182 & 90 & 122 & 110.75 & 5.10 \\
\hline & & Weight (kg) & 182 & 12 & 26 & 17.80 & 3.29 \\
\hline & \multirow{2}{*}{ Girls } & Height $(\mathrm{cm})$ & 126 & 87.9 & 121 & 107.22 & 6.72 \\
\hline & & Weight $(\mathrm{kg})$ & 126 & 12 & 27 & 17.64 & 3.93 \\
\hline
\end{tabular}

The present study revealed that mean head circumference was increased with increasing range of age and mean $\mathrm{HC}$ for boys was higher in comparison with girls. Mean $\mathrm{HC}$ of age range 36 to 47 months among boys and girls are statistically significant (95\% CI: -1.03 to $-0.32 ; p<0.001$ ). Almost same picture was determined by age group
48 to 59 months ( $95 \% \mathrm{CI}:-1.21$ to $-0.48 ; p<0.001)$. However, mean $\mathrm{HC}$ between boys and girls among age range 60 to 71 months was not statistically significant $(p>0.05)$.

Table IV: Mean Head Circumference (HC) based on the age and sex specific distribution of the children

\begin{tabular}{cccccccc}
\hline \multirow{2}{*}{$\begin{array}{c}\text { Age } \\
\text { month }\end{array}$} & Boys & Girls & \multicolumn{6}{c}{ Mean of HC (cm) } \\
\cline { 3 - 8 } & & $\begin{array}{c}\text { Boys } \\
\overline{\boldsymbol{x}} \pm \boldsymbol{S D}\end{array}$ & $\begin{array}{c}\text { Girls } \\
\overline{\boldsymbol{x}} \pm \boldsymbol{S D}\end{array}$ & t value & $\boldsymbol{p}$ value & $\mathbf{9 5 \%} \mathbf{C I}$ \\
\hline $36-47$ & 189 & 193 & $48.17 \pm 1.96$ & $47.49 \pm 1.59$ & -3.72 & $p<0.001$ & -1.03 to -0.32 \\
$48-59$ & 167 & 178 & $48.80 \pm 1.75$ & $47.95 \pm 1.71$ & -4.56 & $p<0.0001$ & -1.21 to -0.48 \\
$60-71$ & 182 & 126 & $48.91 \pm 1.79$ & $48.85 \pm 2.06$ & -0.272 & $p>0.05$ & -0.49 to 0.37 \\
\hline
\end{tabular}

Mean head circumference for age Z-score between boys and girls in age group 36 to 47 months and 48 to 59 months was not significant statistically ( $p$ $>0.05$ ). Whereas, Mean head circumference for age $\mathrm{Z}$-score between boys and girls in age group 60 to 71 months was slightly significant $(p=0.05)$.

Table V: Mean Head Circumference for age Z- score (HCAZ) based on the age and sex specific distribution of the children

\begin{tabular}{cccccccc}
\hline \multirow{2}{*}{$\begin{array}{c}\text { Age } \\
\text { month }\end{array}$} & Boys & Girls & \multicolumn{5}{c}{ Mean of HC (cm) } \\
\cline { 4 - 8 } & & $\begin{array}{c}\text { Boys } \\
\overline{\boldsymbol{x}} \pm \boldsymbol{S D}\end{array}$ & $\begin{array}{c}\text { Girls } \\
\overline{\boldsymbol{x}} \pm \boldsymbol{S D}\end{array}$ & t value & $\boldsymbol{p}$ value & $\mathbf{9 5 \%}$ CI \\
\hline $36-47$ & 189 & 193 & $-1.08 \pm 1.07$ & $-1.12 \pm 1.28$ & -0.33 & $p>0.05$ & -0.27 to 0.19 \\
$48-59$ & 167 & 178 & $-1.26 \pm 1.27$ & $-1.33 \pm 1.40$ & -0.48 & $p>0.05$ & -0.35 to 0.22 \\
$60-71$ & 182 & 126 & $-1.48 \pm 1.14$ & $-1.19 \pm 1.58$ & 1.87 & $p=0.05$ & 0.015 to 0.59 \\
\hline
\end{tabular}

The rate of moderate malnutrition among boys were increasing with the increase of age. Boys with age group 60 - 71 months were more moderately malnourished $(41.2 \%)$ than the other remaining groups. While, severely malnourished children were more frequent in age group $48-59$ months (9.6\%) among boys. The rate of boy's mean malnourishment was increasing with the increase of age. On the other hand, among girls, both of moderate and severe malnourishment were more prevalent in age group $48-59$ months.

Table VI: Distribution of malnourished children according to HC for age.

\begin{tabular}{ccccr}
\hline \multirow{2}{*}{ Gender } & $\begin{array}{c}\text { Age } \\
\text { group } \\
\text { of child }\end{array}$ & $\begin{array}{c}\text { Malnutrition } \\
\text { according to HC }\end{array}$ & Frequency & Percent \\
\hline \multirow{5}{*}{ Boys } & \multirow{2}{*}{$46-47$} & $\mathrm{~A}$ & 50 & 26.5 \\
\cline { 2 - 5 } & \multirow{2}{*}{$48-59$} & $\mathrm{~B}$ & 12 & 6.3 \\
\cline { 2 - 5 } & \multirow{2}{*}{$60-71$} & $\mathrm{~A}$ & 54 & 32.3 \\
& \multirow{2}{*}{$36-47$} & $\mathrm{~A}$ & 16 & 9.6 \\
\cline { 2 - 5 } Girls & $\mathrm{B}$ & $\mathrm{A}$ & 6 & 41.2 \\
& \multirow{2}{*}{$48-59$} & $\mathrm{~B}$ & 53 & 3.3 \\
\cline { 2 - 5 } & \multirow{2}{*}{$60-71$} & $\mathrm{~A}$ & 52 & 11.4 \\
\hline
\end{tabular}

*Note: $\mathrm{A}=$ Moderate Malnourished, $\mathrm{B}=$ Severely Malnourished

According to HAZ, girls were more stunted than their counterparts. The rate of severe, moderate 
and mild stunting among boys were $5.4 \%, 12.30 \%$, $14.10 \%$ and among girls $5.8 \%, 22.5 \%, 22 \%$ respectively.
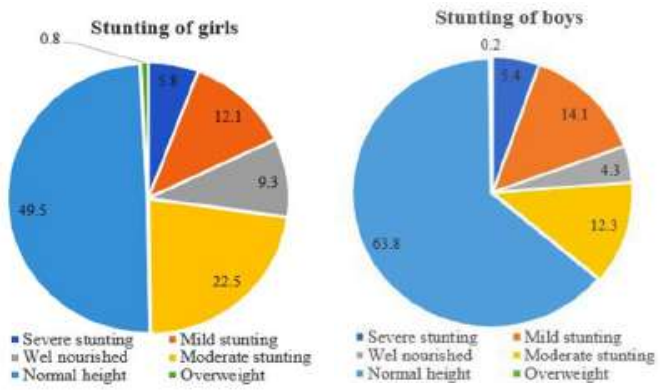

Figure 1: Prevalence of stunting according to HAZ among preschool children in Rajshahi City

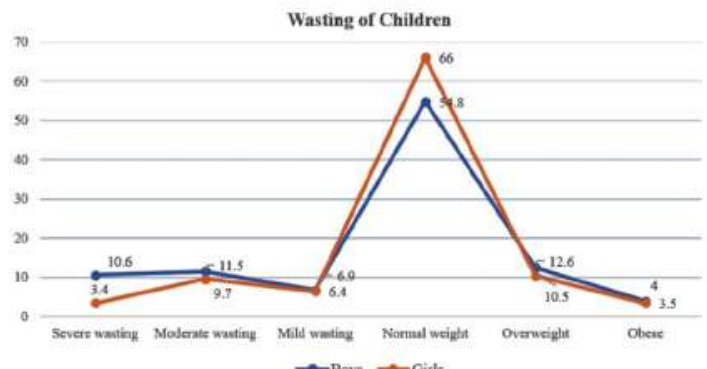

Figure 2: Prevalence of wasting according to WHZ among preschool children in Rajshahi City

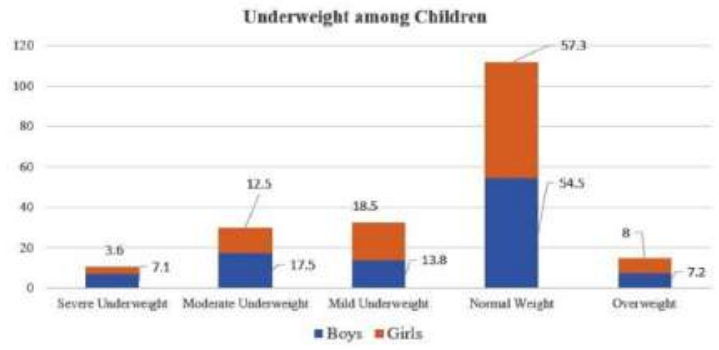

Figure 3: Prevalence of underweight according to WAZ among pre-school children in Rajshahi City

The rate of severe wasting among boys were $10.6 \%$, which is more than three times higher than girls. The prevalence of moderate wasting among boys and girls were $11.5 \%$ and $9.7 \%$ respectively. The study observed that boys were more wasted than that of girls.

In this study, boys were more underweight in comparison to girls. Among boys, the percentage of severe, moderate and mild underweight were $7.1 \%, 17.5 \%$ and $13.8 \%$ respectively, whereas, among girls the percentages were $3.6 \%, 12.5 \%$ and $18.5 \%$ respectively.

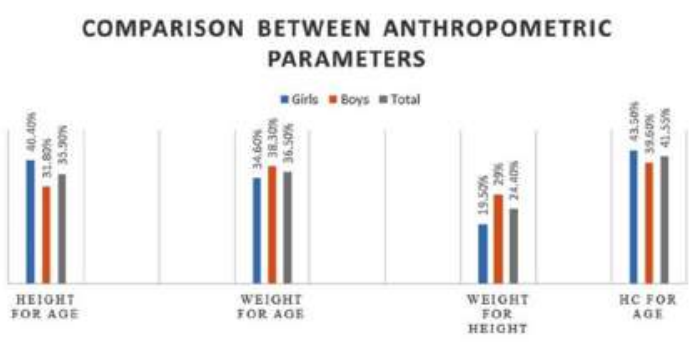

Figure 4: Comparison between anthropometric parameters.

Figure 4 represented, the rate of malnourishment according to $\mathrm{HAZ}, \mathrm{WAZ}, \mathrm{WHZ}$ and $\mathrm{HC}$ for age. The prevalence of malnutrition among children was very high according to $\mathrm{HC}$ for age in comparison to other anthropometric parameters.

Table VII: Association between head circumference for age and nutritional status among pre-school children in Rajshahi Ciy

\begin{tabular}{|c|c|c|c|c|c|c|}
\hline \multirow{2}{*}{ Variables } & \multirow{2}{*}{ Covariates } & \multicolumn{3}{|c|}{ Head circumference for age } & \multirow{2}{*}{$\chi^{2}$} & \multirow{2}{*}{$p$-value } \\
\hline & & $\mathbf{A}$ & B & $\mathbf{C}$ & & \\
\hline \multirow{3}{*}{ Stunting } & & 204 & 55 & 404 & \multirow{3}{*}{6.33} & \multirow{3}{*}{$p<0.05$} \\
\hline & Not stunted & $(30.8 \%)$ & $(8.3 \%)$ & $(60.9 \%)$ & & \\
\hline & Stunted & $\begin{array}{c}124 \\
(33.3 \%)\end{array}$ & $\begin{array}{c}46 \\
(12.4 \%)\end{array}$ & $\begin{array}{c}202 \\
(54.3 \%)\end{array}$ & & \\
\hline \multirow{3}{*}{ Underweight } & Not & 172 & 53 & 432 & \multirow{3}{*}{38.45} & \multirow{3}{*}{$p<0.001$} \\
\hline & underweight & $(26.2 \%)$ & $(8.1 \%)$ & $(65.8 \%)$ & & \\
\hline & Underweight & $\begin{array}{c}156 \\
(41.3 \%)\end{array}$ & $48(12.7 \%)$ & $\begin{array}{c}174 \\
(46 \%)\end{array}$ & & \\
\hline \multirow{3}{*}{ Wasting } & & 222 & 77 & 483 & \multirow{3}{*}{\multicolumn{2}{|c|}{$16.67 p<0.001$}} \\
\hline & Not wasted & $(28.4 \%)$ & $(9.8 \%)$ & $(61.8 \%)$ & & \\
\hline & Wasted & $\begin{array}{c}106 \\
(41.9 \%)\end{array}$ & $\begin{array}{c}24 \\
(9.5 \%)\end{array}$ & $\begin{array}{c}123 \\
(48.6 \%)\end{array}$ & & \\
\hline
\end{tabular}

*Note: $\mathrm{A}=$ Moderate malnourished, $\mathrm{B}=$ Severely malnourished, $\mathrm{C}=$ Normal

It was observed that association between stunting, underweight, wasting and head circumference for age were statistically significant among pre-school children in Rajshahi City. Nearly $46 \%$ of stunted, $54 \%$ of underweight and $51.4 \%$ wasted children were somehow severely and moderate malnourished according to $\mathrm{HC}$ for age. The study identified that normal $\mathrm{HC}$ for age is vital for better nutritional status of children.

\section{Discussion}

Head circumference, a non-invasive and inexpensive anthropometric indicator of both nutritional background and brain development. ${ }^{22,23}$

In the present study, according to HCAZ, 33.3\% of boys and $30 \%$ of girls were moderately malnourished and on the other hand, 6.3 of boys and $13.5 \%$ of girls were severely malnourished. Another findings reported by Badami et al. had shown that overall malnourishment among boys and girls $37.03 \%$ and $28.23 \%$ respectively in an urban slum area of Karnataka, India. ${ }^{24}$ In another study conducted at Kolkata, India, Mandal and 
Bose, have reported a very high prevalence of overall malnutrition using $\mathrm{HC}$, where over all malnutrition of $62.8 \%$ among boys and $64.9 \%$ among girls. ${ }^{25}$ This high rate of malnutrition would be happened to village area of the children sampled with low economic status, lack of education, poor health facilities exist.

Present study revealed that girls were more affected by undernourishment problems according to $\mathrm{HC}$ than boys. Opposite findings identified by Badami et al. where boys were more malnourished in comparison to girls (boys: 37\%, girls: 28\%). Mandal and Bose, revealed same result of undernutrition (boys: 64.9\%; girls: 62.8\%) among boys than girls of rural pre-school children of Hooghly district of West Bengal. ${ }^{25}$ However, similar result was shown by Tigga PL et al. where malnourishment was higher among girls than boys. $^{26}$ The overall prevalence of undernutrition according to the $\mathrm{HC}$ among girls seemed to be higher $(58.2 \%)$ than that in case of boys $(53.9 \%)$, yet this difference was statistically not significant $(p>0.05)$. Significantly lower prevalence of malnutrition $(p<0.05)$ was reported among Bengalee pre-school boys of Midnapore, West Bengal (boys: 19.2\%; girls: 22.6\%) $(p<0.05)$ by Maiti et al., 2012. ${ }^{27}$

Present study reported that malnutrition increased with increasing of age in case of boys. Among boys, the rate of malnutrition was $32.8 \%$ for age group 36 to 47 months, whereas, for age group 60 to 71 months, the malnutrition rate was $44.5 \%$, and on the other hand, among girls, the rate of malnutrition was highly prevalent in age group 48 - 59 months $32 \%$ moderately malnourished and $17.4 \%$ severely malnourished) Opposite result was shown by Maiti et al. where decreasing prevalence of malnutrition with increasing of age. ${ }^{27}$ However similar result was reported by Mandal and Bose in 2010, where increasing prevalence of malnutrition with increasing of age. ${ }^{25}$ The variation of the results may be due to socio-economic and demographic condition of parents, literacy level of parents, nutritional knowledge of parents, food habit, environmental hygiene, food security etc.

In the present study, moderate malnutrition was more prevalent than severe malnutrition. Many other studies, conducted by Badami et. al. Mandal and Bose, 2010, Tigga et al. had supported the same findings. ${ }^{24-26}$

The result of present study reported that mean values of $\mathrm{HC}$ to be significantly lower among girls $(48.00 \pm 1.84)$ than that of boys (48.62 \pm 1.87$)$. Similar study conducted by Zaki et al. which held into Egyptian children suggested mean $\mathrm{HC}$ values were significantly lower in girls than boys. ${ }^{28}$ From literature review, it was observed that there was no research work, which determined the correlation between stunting, underweight, wasting and $\mathrm{HC}$ for age.

\section{Conclusion}

The present study reflects that the risk of malnutrition according to $\mathrm{HC}$ for age is very high in Rajshahi city Bangladesh. As HC for age is related to the brain's growth and development, cognitive development, IQ level, capability of learning and proper nutrition are all interrelated. Intervention programme should, therefore, be taken on improving the nutritional status of these children along with a regular monitoring of their health so that they achieve their optimal physical growth potentials. Children wellbeing programme should concentrate for improving health consciousness, nutritional education, education level of guardians, ensure vaccination and supplementation of micronutrients, developed sanitation and hygiene, regular health screening and timely treatment of childhood illnesses nationally.

Conflict of interest: Authors declare that there was no conflict of interests in relation to this study.

\section{Acknowledgement}

We acknowledge the all cooperation and support of the children and their parents in Rajshahi city, who actively participated in this study.

\section{References}

1. Frison S, Kerac M, Checchi F, Prudhon C. Anthropometric indices and measures to assess change in the nutritional status of a population: a systematic literature review. BMC Nutrition. 2016; 2: 76.

2. Physical status: The use and interpretation of anthropometry: Technical report series. Geneva: World Health Organization; 1995. WHO. Report 
Yeasmin and Yeasmin

No.:854 Available from: https://apps.who.int/iris/bitstream/handle/10665/37003 /WHO_TRS_854.pdf;jsessionid $=91698459 \mathrm{BC} 628 \mathrm{BE}$ B0B0AC7CF8C9EA362? sequence $=1$

3. Rahman A, Hakim AM. Malnutrition Prevalence and Health Practices of Homeless Children: A CrossSectional Study in Bangladesh. Science Journal of Public Health.Special Issue: Childhood Malnutrition in Developing Countries. 2016; 4, (1): 10-15. doi: 10.11648/j.sjph.s.2016040101.13

4. Ruel MT, Alderman H, and the Maternal and Child Nutrition Study Group. Nutrition-sensitive interventions and programmes: how can they help to accelerate progress in improving maternal and child nutrition. The Lancet, 2013. http://dx.doi.org/10.1016/S0140- 6736(13)60843-0.

5. ACC/SCN. Commission on the nutrition challenges of the 21th century. Ending malnutrition by 2020: an agenda for change in the Millennium. Food and Nutr. Bull.2000; 21(3) supplement: 1-88.

6. Das S and Gulshan J. Different forms of malnutrition among under five children in Bangladesh: a cross sectional study on prevalence and determinants. BMC Nutrition BMC series - open, inclusive and trusted. 2017; 3:1 DOI: 10.1186/s40795-016-0122-2

7. Chen LC, Chowdhury AKMA, \& Huffman SL. Anthropometric assessment of energy-protein malnutrition and subsequent risk of mortality among preschool aged children. American Journal of Clinical Nutrition 33, 1980, $1836-1845$.

8. Johnson MD, Yamanaka WK, Formacion CS. A comparison of anthropometric methods for assessing nutritional status of preschool children: the Philippines study. J Trop Pediatr. 1984 Apr; 30(2):96-104.

9. WHO Multicentre Growth Reference Study Group. WHO Child Growth Standards: Head circumferencefor-age, arm circumference-for-age, triceps skinfoldfor-age and subscapular skinfold-for-age: Methods and development. Geneva: World Health Organization, 2007; 1-237 Available from: https://www.who.int/childgrowth/standards/second_se t/technical_report_2.pdf?ua $=1$

10. Plaza LB, Brito IN, Torrejón PH, Gloor CV, Medina JJM, Díaz TT, et al. The impact of malnutrition on brain development, intelligence and school work performance. Arch Latinoam Nutr. 2001; 51: 64-71.

11. Laron Z, Iluz M, Kauli, R. Head circumference in untreated and IGF-I treated patients with Laron syndrome: comparison with untreated and hGHtreated children with isolated growth hormone deficiency. Growth Horm IGF Res. 2012; 2: 49-52.

12. Ivanovic DM, Leiva BP, Pérez HT, Olivares MG, Díaz NS, Urrutia MS, et al. Head size and intelligence,
Head circumference in preschool children

learning, nutritional status and brain development. Head, IQ, learning, nutrition and brain.Neuropsych. 2004; 42: 1118-31.

13. Menkes JH. Texbook of Child Neurology 1995.Baltimore, MD:Williams and Wilkins.

14. Ivanovic D, Leiva B, Pe'rez $\mathrm{H}$, Inzunza N, Almagia` $\mathrm{A}$, Toro $\mathrm{T}$ et al. Long-term effects of severe undernutrition during the first year of life on brain development and learning in Chilean high school graduates. Nutrition 2000; 16: 1056- 1063.

15. Australian Institute of Health and Welfare. National Maternity Data Development Project: Baby head circumference-Research brief no. 3. Cat. no. PER 77. Canberra: AIHW.2016; 1-8. Available from: https://www.aihw.gov.au/getmedia/5da3aa2f-2d0341bc-960d58abb87b4f0f/brief_3_per-77.pdf.aspx

16. Tison AC, Gosselin J \& Rivard IC. Head growth and cranial assessment at neurological examination in infancy. Developmental Medicine and Child Neurology. 2002; 44:643-8.

17. Biswas S, Bose K, Mukhopadhyay A, et al. Midupper Arm Circumference Based Undernutrition among Bengalee Children of Chapra, West Bengal, India. Iran J Pediatr. 2010; 20(1):63-68.

18. Alderman H, Hentschel J, Sabates R. With the help of one's neighbors: externalities in the production of nutrition in Peru. Soc Sci and Med. 2003; 56(10):2019-31.

19. Inam MSB. Non-malnourished under five children in Dhaka slums: Associated factors and behaviors. A Research Protocol Study. Umea International School of Public Health, Sweden. 2006-2007. Available from: https://www.umu.se/institutionen-for-folkhalsa-ochklinisk-medicin/digitalAssets/30/30081_2007-8-md.shanjad-bin-inam.pdf

20. Duderstadt K. Pediatric physical examination: an illustrated handbook.2nd ed. Missouri: Mosby Elsevier;2014.

21. WHO, WHO child growth standards, Length/Heightfor-age, Weight-forage, weight-for-length, weight-forheight, body mass index-for-age, Methods and development, June 2012. Available at: https://www.who.int/childgrowth/standards/Technical _report.pdf

22. Ivanovic DM, Leiva BP, Pe'rez HT, Almagia AF, Toro TD,Urrutia MS et al. Nutritional status, brain development and scholastic achievement of Chilean high-school graduates from high and low intellectual quotient and socio-economic status. British Journal of Nutrition. 2002; 87, 81-92.

23. Vernon PA, Wickett JC, Bazana PG, Stelmack RM. The neuropsychology andpsychophysiology of human intelligence. In R. J.Sternberg (Ed.), Handbook of 
intelligence.Cambridge: Cambridge University Press. 2000; 245-264.

24. Badami SV, Mahesh BC, Chinagudi SS, Patil S, \& Gadwal R. Assessment of Nutritional Status of Preschool Children Using Head Circumference. International Journal of Current Medical and Applied Sciences. 2014;4:72-75.

25. Mandal GC \& Bose K. Undernutrition among the rural preschool children (ICDS) of Arambag,Hooghly district, West bengal, India, using new head Circumference cut-off points. International Journal of Current Research 2010;10:007-011

26. Tigga PL, Mondal N and Sen J. Head circumference as an indicator of undernutrition among tribal preschool children aged 2-5 years of North Bengal, India. Human Biology Review.2016; 5 (1), 17-33.

27. Maiti S, Ali KM, Ghosh D, Paul S. Assessment of Head Circumference among Pre-school Children of Midnapore Town, West Bengal using WHO (2007) Recommended Cut-off Points. International Journal of Preventive Medicine. 2012; 3(10):742-44

28. Zaki ME, Hassan NE, El-Masry SA. Head circumference reference data for Egyptian children and adolescents. East Mediterr Health J. 2008; 14: 69-81. 